\title{
TECNOLOGIAS SOCIAIS HÍDRICAS PARA CONVIVÊNCIA COM O SEMIÁRIDO: O CASO DE UM ASSENTAMENTO RURAL DO MUNICÍPIO DE CABACEIRAS - PB
}

\author{
S. D. SILVA*, V. P. MEDEIROS e A. B. SILVA \\ Universidade Federal da Paraíba \\ suayzedouglas@hotmail.com*
}

Artigo submetido em agosto/2015 e aceito em janeiro/2016

DOI: $10.15628 /$ holos.2016.3312

\begin{abstract}
RESUMO
O estudo tem como objetivo compreender o uso de tecnologias sociais hídricas para a convivência com o semiárido no assentamento Serra do Monte, situado no município de Cabaceiras-PB, na região do Cariri paraibano. Nessa região, a semiaridez e a escassez de água se mantiveram, historicamente, embasadas na concepção de combate às secas. Contudo, desde o ano de 2000 vem ocorrendo uma mudança paradigmática no que se refere à formulação das políticas e ações pautadas pela concepção de convivência com o semiárido. Uma dessas mudanças ocorre com a difusão de tecnologias sociais, oriundas de práticas não agressoras ao meio ambiente, que estão contribuindo para a valorização de saberes e técnicas e para a melhoria das condições de vida da população local. O estudo em pauta apoia-se na abordagem descritiva-reflexiva como referencial para a
\end{abstract}

a nálise das experiências e dos resultados decorrentes dos usos de tecnol ogias sociais e práticas des envolvidas pelos assentados. O estudo foi realizado por meio dos seguintes procedimentos: levantamento bibliográfico, coleta de dados secundários e trabalhos de campo para registros fotográficos e entrevistas com as lideranças locais. Conclui-se que as tecnologias sociais hídricas, embora estejam amenizando os efeitos das secas periódicas, não são suficientes para a consolidação do paradigma da sustentabilidade e da convivência com o semiárido na área pesquisada. Apesar da importância assumida pelas tecnologias sociais hídricas aqui estudadas, a sua implantação e a própria visão de convivência com o semiárido ainda requerem maior articulação com ações voltadas às mudanças es truturais.

PALAVRAS-CHAVE: Assentamento Serra do Monte, Políticas públicas, Tecnologias sociais hídricas.

\section{WATER SOCIAL TECHNOLOGIES TO THE COEXISTENCE WITH THE SEMI-ARID: A STUDY CASE OF A RURAL SETTLEMENT IN THE MUNICIPALITY OF CABACEIRAS - PB}

\begin{abstract}
The study aims to understand the use of water technologies to the social coexistence with the semiarid in Serra do Monte settlement, situated in the municipality of Cabaceiras-PB, in the Cariri region. In this region, semi-arid condition and water shortages remained historically based on the conception of combat droughts. However, since 2000 there has been a paradigm shift with regard to the formulation of policies and actions guided by the concept of coexistence with the semiarid region. One such change occurs with the spread of social technologies, from non aggressive practices on the environment, which are contributing to the enhancement of knowledge and techniques and to improve the living conditions of local people. The agenda for study is based on descriptive-reflective approach as a
\end{abstract}

reference for the analysis of experiences and results stemming from the social technologies of customs and practices developed by the settlers. The study was conducted by means of the following: literature, secondary data collection and field work for photographic records and interviews with local leaders. We conclude that water social technologies, although they are mitigating the effects of periodic droughts, they are not enough to consolidate the paradigm of sustainability and coexistence with the semiarid in the research area. Despite the importance assumed by water social technologies in the present study, their implementation and their own vision of coexistence with the semiarid still require greater coordination with actions to structural changes.

KEYWORDS: Serra do Monte rural settlement, Public policies, Water social technologies. 


\section{INTRODUÇÃO}

Geralmente, quando se fala em semiárido se pensa de início que é uma região desértica, de espaços do atraso e com a presença de populações famintas, animais mortos e solos rachados pela falta de água. Ou seja, espalharam a ideia de que o semiárido é uma região que tem como traço marcante a pobreza extrema. Tais concepções são, ao mesmo tempo, real e ideológica, pois na maioria das vezes servem para atribuir à natureza problemas políticos, sociais e econômicos que foram historicamente construídos e propagados pelos homens que detém os meios de produção, isto é, os donos do poder.

O semiárido brasileiro, caracteristicamente, apresenta precipitação anual máxima de 800 $\mathrm{mm}$, insolação média de $2.800 \mathrm{~h} / \mathrm{ano}$, temperaturas médias anuais de $23 \circ \mathrm{C}$ a $270 \mathrm{C}$, evaporação média de $2.000 \mathrm{~mm}$ anuais e umidade relativa do ar de aproximadamente $50 \%$. Um dos principais fatores para a ocorrência dos fenômenos das secas é a reduzida precipitação pluviométrica marcada pela variabilidade interanual (ANDRADE, 1977; NIMER, 1979; DUQUE, 2001; SILVA; MOURA; KIILL et al., 2010).

O Cariri paraibano (Mapa 01), região localizada na porção Centro-Sul do Estado da Paraíba, e onde está localizado o recorte espacial do estudo, tem uma extensão territorial de aproximadamente $11.192,01 \mathrm{Km}^{2}$, o que equivale a pouco mais de $20 \%$ do território paraibano. É composta por vinte e nove municípios, sendo doze inseridos no Cariri Oriental e dezessete no Cariri Ocidental, e conta com uma população total de 185.235 habitantes, dos quais 79.696 habitam na zona rural (IBGE, 2010). Os Cariris Velhos (como é conhecido todo o Cariri paraibano) têm como elementos comuns do seu conjunto de paisagens os baixos índices pluviométricos, as temperaturas médias elevadas, déficits hídricos acentuados, a caatinga hiperxerófila, a ocorrência de secas periódicas e as limitações do solo, os quais são rasos e muitas vezes apresentam alto teor de salinidade, o predomínio de cidades pequenas e a baixa densidade demográfica (SOUZA, 2008).

Entretanto, esse recorte espacial no Estado da Paraíba está subdividido em Oriental e Ocidental. O oriental apresenta características ambientais um pouco diferente, posto apresentar médias pluviométricas mais baixas (400 a 500mm/ano), relevo com topografia suave ondulada a ondulada e uma economia predominantemente pastoril, onde merece destaque a criação de caprinos e ovinos. Já no ocidental, a situação ambiental é caracterizada por médias pluviométricas um pouco maiores (500 a $600 \mathrm{~mm} / \mathrm{ano}$ ), o relevo apresenta-se com declividade acentuada e a economia é mais dinâmica, tanto na pecuária como na agricultura.

A localização do Cariri Oriental exerce papel fundamental na compreensão dos baixos índices pluviométricos aí dominantes. Isso porque ele está situado no fim do percurso dos fluxos úmidos que se direcionam para o semiárido nordestino e em situação de sotavento, fazendo parte da diagonal mais seca do Brasil, com médias pluviométricas de cerca de $500 \mathrm{~mm} /$ ano (NIMER, 1979). 


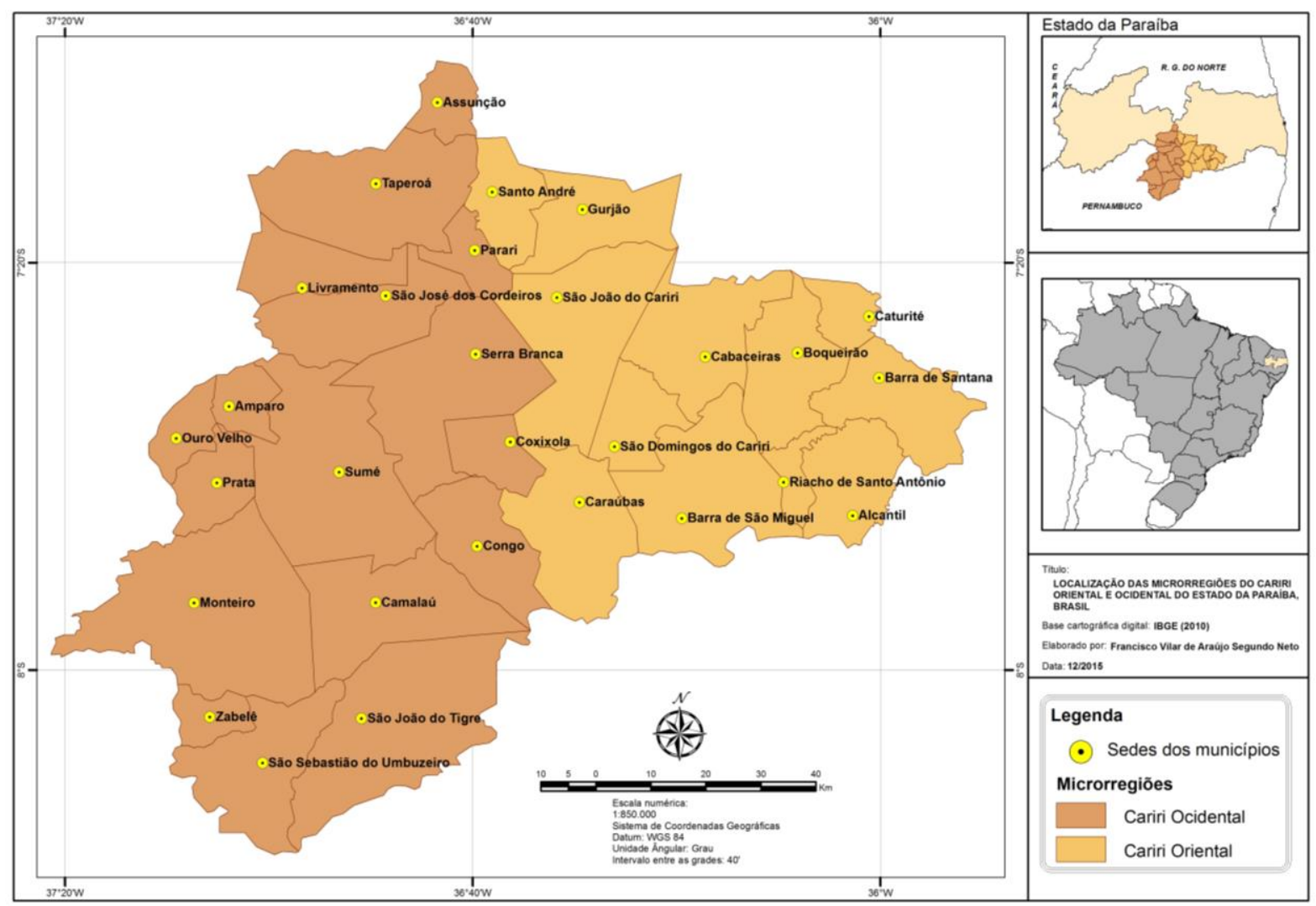

Mapa 01: Localização da região do Cariri paraibano.

Nesse contexto, o aspecto climático é o elemento natural que mais chama atenção na região do Cariri paraibano, especialmente no município de Cabaceiras, já que este apresenta os menores índices pluviométricos do país, com totais pluviométricos de $279 \mathrm{~mm}$ anuais, como menciona Cabral (1977). O município de Cabaceiras possui uma área de $453 \mathrm{~km}^{2}$ e uma população total de 5.035 habitantes, dos quais 2.818 residem na zona rural, conforme dados do IBGE (2010).

As características climáticas do Cariri paraibano, sobretudo do município de Cabaceiras, nos levaram a refletir sobre o papel desempenhado pelas tecnologias sociais hídricas, sobretudo nos espaços rurais, para a reprodução da vida e para a permanência no campo.

Após viagens exploratórias e coleta de dados preliminares optou-se por realizar o estudo no assentamento Serra do Monte (Mapa 02), o qual se encontra a uma distância de $16 \mathrm{~km}$ da cidade de Cabaceiras. O Serra do Monte possui uma área de 5,127, 2197 hectares, estando dividido em lotes de 36 a 38ha para cada uma das 101 famílias residentes. Além disso, existem 1.047,3733ha de Reserva Legal e 179,3726ha de área de Preservação Permanente.

De acordo com o que consta no Plano de Recuperação do Assentamento Serra do Monte (2010), o Instituto Nacional de Colonização e Reforma Agrária (INCRA) publicou, em 1996, no jornal O Norte a relação dos 15 maiores imóveis improdutivos do Estado da Paraíba, sendo um deles a Serra do Monte, com 5,830,6ha. Após o falecimento do seu proprietário, João Francisco da Motta, o imóvel foi colocado à disposição do INCRA para a realização da política de Reforma Agrária. 


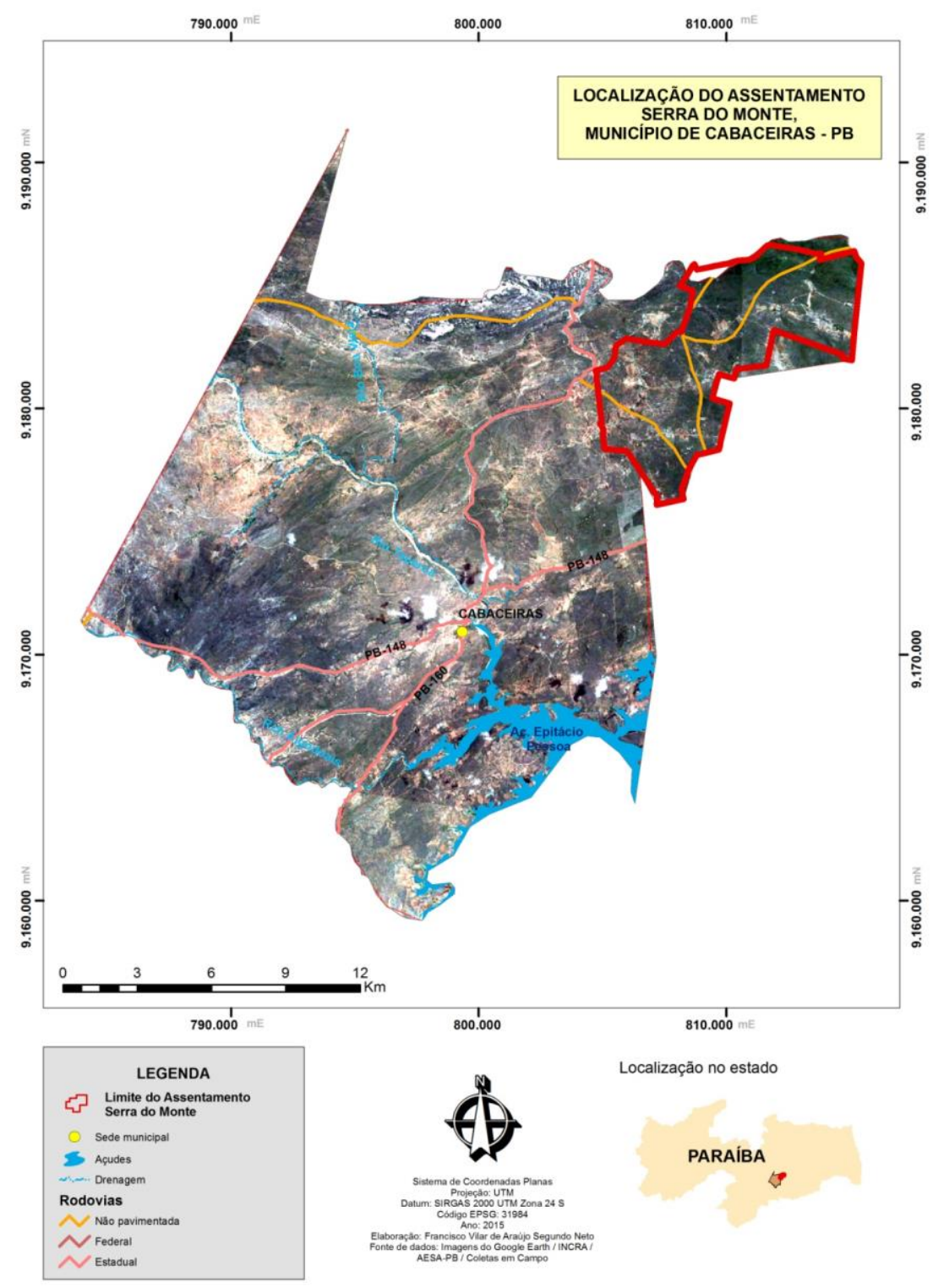

Mapa 02: Recorte espacial da área de estudo.

Fonte: Silva (2015).

Conforme consta no referido plano, a propriedade era caracterizada pela pecuária extensiva. Na infraestrutura do imóvel havia um abatedouro de animais e o beneficiamento de peles era realizado nos curtumes da família, na cidade de Campina Grande (PB) e Natal (RN). A criação de animais de forma extensiva provocou sérios agravos ambientais, como retirada da vegetação nativa para diversos usos: alimentar o gado, produzir carvão e utilizar madeira na construção de cercas e currais na região.

Após a emissão dos títulos de posse, os investimentos e as benfeitorias realizadas atingiram ao valor de $\mathrm{R} \$ 356.578,58$, correspondendo a uma capacidade preestabelecida na Portaria /INCRA/SR-18/№10/2000, de 11 de fevereiro de 2000, para criação do PA e a instalação de 170 famílias (PLANO DE RECUPERAÇÃO DO ASSENTAMENTO SERRADO MONTE CABACEIRAS-PB, 2010).

Devido à ausência de infraestrutura, o que dificultava a vida dos assentados e tornava pouco atrativo o lugar, apenas dezessete famílias foram morar no assentamento. Com a criação da 
Escola Municipal de Ensino Fundamental João Francisco da Motta, em 06 de fevereiro de 2005, e o estabelecimento de outros equipamentos coletivos, é que as famílias beneficiadas com o título de posse começaram a residir no local.

No assentamento Serra do Monte, assim como em todo o semiárido Nordestino, existem problemas estruturais e de ordem natural que dificultam o desenvolvimento social e econômico da região. Tratam-se principalmente de deficiências hídricas, resultado de uma baixa e irregular precipitação anual, associado a uma elevada taxa de evaporação e evapotrans piração e a presença de solos rasos e pedregosos. Tais características impõem restrições ao sistema produtivo da área de estudo, além de provocar sérios danos sociais ao atingir principalmente a população economicamente mais pobre.

$\mathrm{Na}$ área delimitada para realização do estudo, bem como em toda a região do Cariri paraibano, a semiaridez e a escassez de água se mantiveram historicamente aliadas a pouca eficiência de políticas públicas ${ }^{1}$, as quais estiveram pautadas pela concepção de combate às secas e na diminuição de seus efeitos. Nesse processo, a população, principalmente àquela que habita a zona rural, foi afastada de ações que pudessem favorecer a construção de novas alternativas a serem materializadas, por exemplo, em um plano sólido de convivência com o semiárido.

O estudo das tecnologias sociais voltadas para esta convivência tem surgido e se expandido como estratégias de adaptação e de mitigação de problemas decorrentes de secas constantes e de políticas públicas destoantes da realidade espacial local. Mas, pouco ou quase nada tem sido compreendido e analisado no âmbito da Geografia paraibana sobre os pontos críticos (fortaleza e debilidades) da difusão das tecnologias sociais hídricas pelo o Cariri paraibano. Contribuir para o preenchimento dessa lacuna também é um dos objetivos da pesquisa.

Para a realização do estudo sobre o uso de tecnologias sociais hídricas como uma das convivências do semiárido, em particular no assentamento Serra do Monte, diversos procedimentos de pesquisa foram utilizados, dentre eles, destacam-se: levantamento bibliográfico, coleta de dados secundários e trabalhos de campo, com a realização de entrevistas semiestruturadas com as lideranças locais, conversas informais com os assentados e registros fotográficos. Esses procedimentos de pesquisa foram utilizados no intuito de ampliarmos o conhecimento teórico sobre os conceitos que norteiam a pesquisa, estabelecer uma aproximação com a temática do trabalho e manter o contato com a realidade vivenciada pelos os sujeitos sociais. A análise das experiências e dos resultados decorrentes dos usos de tecnologias sociais e práticas voltadas à convivência com o semiárido está fundamentada em uma abordagem descritivareflexiva.

Portanto, o presente estudo objetiva compreender o uso de tecnologias sociais hídricas para a convivência com o semiárido no assentamento Serra do Monte, situado no município de Cabaceiras-PB, na região do Cariri paraibano.

\footnotetext{
1 Entende-se por políticas estatais ou políticas públicas as decisões no Estado de determinar a sua presença orgânica concreta nas diferentes esferas da sociedade. Essa presença se efetiva por meio das funções do Estado de tal modo que as políticas e sua prática são expressas institucionalmente pelas leis, programas e projetos, dentre outros.
} 


\section{RESULTADOS E DISCUSSÃO}

A partir dos suportes teóricos adotados e da pesquisa de campo realizada, os resultados do estudo apontam que durante muito tempo a situação de fome, pobreza e atraso econômico do Nordeste foi debitada na conta das secas, das condições físico-climáticas da região. Tal pensamento desencadeou o surgimento de uma série de proposições que apresentavam soluções voltadas para o combate à seca e não aos seus efeitos, numa tentativa de mudar a realidade natural. O fato é que grande parte dos estudos feitos do século XVII até meados do século XX sugeriam a solução hidráulica como forma de tentar "salvar o Nordeste", prevalecendo, dentre esta, a construção de grandes reservatórios de água e a irrigação (SILVA, 2010).

Essa maneira de compreender os problemas do semiárido, considerando a falta de água como o único, provocou o surgimento da indústria da seca ${ }^{2}$, vista como um caminho seguro para a (re) configuração ou (re) produção do domínio político das oligarquias locais ${ }^{3}$. Para isso, as ações emergenciais contribuíram mais para mascarar a realidade do que transformá-la. A política praticada nas áreas afetadas pelas estiagens ainda se fundamenta no assistencialismo sazonal, já que durante a seca o governo federal auxilia os municípios atingidos com a liberação de verbas, distribui cestas básicas para a população mais pobre e o perdoa, total ou parcial, as dívidas contraídas, principalmente, por empresários e fazendeiros. Nessa lógica, os fazendeiros e os empresários são beneficiados, enquanto o restante da população, os que realmente precisam, poucos são contemplados pelas ações governamentais. Assim, pensar o semiárido a partir apenas do período seco é cair nas armadilhas dos concentradores de riquezas, que têm a água e a terra como elementos para o estabelecimento de relações de poder.

Desse modo, as intervenções que ocorreram aolongo dos anos no território semiárido e a atuação das oligarquias nordestinas permite afirmar que a seca foi um meio para se conseguir investimentos governamentais na região, para o estabelecimento de políticas de favores e, sobretudo, para efetivação do conceito de combate às secas. Para muitos estudiosos do semiárido, o combate a seca é um grande equívoco.

Desde o período colonial, a intervenção governamental vem sendo feita visando 'lutar contra a seca' e não 'lutar contra os efeitos da seca'. Esquecem-se os nossos administradores que a seca, como tal, não pode ser combatida, de vez que é um fenômeno natural. Na realidade, o que deve ser feito é uma conscientização da população visando à adaptação à seca e travar luta para atenuar seus efeitos (ANDRADE, 1999, p.47).

Em outras palavras, o autor destaca que o semiárido nordestino vem sofrendo com o problema das secas há várias décadas. Estas secas se explicam em parte pelas altas temperaturas registradas na região, o que, entre outras coisas, acarreta uma elevada taxa de evaporação. Desta forma, não se faz possível à permanência de alguns corpos d'água, e a maioria dos rios tornam-se

\footnotetext{
2 Trata-se de uma prática na qual os grupos políticos e seus aliados se aproveitam das secas periódicas que ocorrem na região Nordeste para se apropriarem de recursos públicos com o pretexto de combatê-las (FERREIRA, 1993).

3 "Em seu sentido etimológico significa que a autoridade se concentra nas mãos de poucas pessoas, podendo estas pertencerem ao mesmo partido político, classe social ou família. No caso brasileiro, o sistema oligárquico se fundamentou na estrutura familiar e na classe dos proprietários de terra" (FERREIRA, 1993, p.18).
} 
intermitentes ${ }^{4}$. Estes fatores naturais, associados às próprias ações humanas - que utilizam o solo, a água e a vegetação de forma predatória - agravam ainda mais a situação.

É certo que as condições que predominam no Nordeste do Brasil podem, relativamente, dificultar a vida, exigir maior empenho e maior racionalidade na gestão dos recursos naturais, em geral, e da água, em particular, mas não podem ser responsabilizadas pela pobreza e pela cultura das secas no semiárido nordestino, como ressaltado por Rebouças (1997).

O combate contra os efeitos das secas na região Nordeste se deu de muitas formas, mesmo que algumas destas ações tenham sido pouco eficientes. $O$ que se pode concluir a partir das leituras feitas sobre a realidade do semiárido nordestino é que o principal viés de enfrentamento aos efeitos da seca foi a adoção de políticas públicas voltadas à construção de açudes e barragens, instalação de perímetros irrigados e a construção de canais por todo o seu território, configurandose, portanto, uma exorbitante tecnificação e uma indisfarçável despolitização da questão. Assim, durante anos, a construção de açudes foi vista como a alternativa mais viável e eficaz para o abastecimento de água, uma vez que acreditava ser esta a forma mais adequada de solucionar o problema de falta de água na região semiárida.

Foi nesse contexto, através do decreto 7.619 de 21 de outubro de 1909, durante ogoverno de Nilo Peçanha, que foi criado o órgão responsável pela construção e monitoramento dos açudes na região Nordeste, isto é, a Inspetoria de Obras Contra a Secas (IOCS), o qual foi o primeiro órgão a estudar a problemática do semiárido. É a partir desse momento que se tem início a prática e a concepção de implantação de políticas permanentes, de grandes investimentos e de grandes projetos de açudagem, como forma de "salvar" a região das calamidades provocadas pelas secas, as quais foram consolidadas com a atuação do Instituto Federal de Obras Contra a Seca (IFOCS), antigo IOCS, criado em 1919 sob o decreto 13.687 e do Departamento Nacional de Obras contra as Secas (DNOCS), ex-IFOCS, criado em 28 de dezembro de 1945, pelo decreto-lei 8.846, e tornando-se uma autarquia federal, através da Lei no 4.229 de 01/06/1963.

Até por volta de 1959, o DNOCSera praticamente o único órgão do governo federal atuando na execução de obras de engenharia na região, como construção de açudes, ferrovias, hospitais, campos de pouso e usinas hidrelétricas, entre outras ações. Seguindo esta política, o DNOCS foi responsável pela construção de 310 açudes públicos e 662 barragens privadas em propriedades de grandes e médios fazendeiros (OLIVEIRA, 1981).

Com a criação da Superintendência de Desenvolvimento do Nordeste (SUDENE) em 1959, pela Lei no 3.692, durante o governo de Juscelino Kubitscheck, a intervenção federal na região tornou-se, ou pelo menos tentou ser, desenvolvimentista, e os programas de aproveitamento hídrico incorporaram as dimensões econômicas e sociais, por muitas vezes esquecidas, pelos demais órgãos que atuavam no Nordeste.

Não é preciso uma profunda análise das informações acima para percebemos que o poder público, desde a criação dos órgãos citados anteriormente, sempre desempenhou uma política de açudagem no Nordeste, favorecendo os grandes latifundiários com a construção de barragens

\footnotetext{
${ }^{4}$ Rios que correm durante a época das chuvas. Estes rios, segundo o linguajar dos sertanejos, "cortam" na época das chuvas (SILVA, 2012, p.12).
} 
particulares, e outros tipos de favorecimentos. Mesmo com a criação da SUDENE, estes órgãos nunca tiveram o sucesso esperado, em seus objetivos e metas. Na verdade, sempre ocorreram ações que possibilitaram a reprodução da "indústria das secas".

Ab'Saber (1999), por exemplo, criticava severamente essas políticas públicas, as quais se mostraram inadequadas para uma convivência com a seca e para o estabelecimento de condições adequadas de vida daqueles que habitam uma região bastante castigada por processos naturais e pelas perversões oriundas de uma injusta distribuição da renda e da terra e de forte atuação política das oligarquias locais. Para esse autor, além de uma reforma na estrutura agrária regional, "é preciso, ainda, adotar-se padrões mais polivalentes de produção, de modo a garantir a continuidade da produção rural em todos os tipos de tempo. É não dar tréguas às oligarquias locais, imbatíveis na sua maciça insensibilidade humana" (AB'SABER, 1999, p.36).

É importante destacar que a imagem do Nordeste, tantas vezes associada ao flagelo decorrido unicamente da semiaridez e das secas, começou a ser desmistificada na primeira metade do séculoXX. Na década de 1930, por exemplo, Djacir Menezes, em seu livro "O Outro Nordeste" mostra, dentre outras coisas, como o banditismo (manifestação violenta) e o fanatismo religioso (manifestação passiva) eram, ambas, formas de reações da população sertaneja contra as condições em que se encontravam, sendo estas oriundas não só das próprias características naturais do sertão, mas também das injustiças sociais provocadas pela busca sedenta das oligarquias sertanejas por terras e riqueza (SILVA, 2010).

Não menos importante foi à contribuição de Josué de Castro contida na obra Geografia da Fome, publicada no final da década de 1940. O autor apontava como causas da calamidade nos períodos de seca a concentração de terra e a exploração do trabalho (como o regime de arrendamento, por exemplo), ocultos num sistema socioeconômico que não permitia a formação de quaisquer reservas de alimento por parte das populações mais pobres nos períodos de escassez. Também assinalava, com bastante propriedade, a educação, a revolução cultural e a orientação política do povo, como caminhos para a superação da pobreza e da fome no semiárido. Além disso, destacava a necessidade de uma mudança estrutural do sistema socioeconômico e político, ao propor, por exemplo, projetos de desenvolvimento econômico do Nordeste num contexto de uma política nacional de desenvolvimento. Tudo isso pressupõe uma mudança significativa no modelo de desenvolvimento, como ressaltado por Silva (2010).

Ao estudar os contextos históricos e as formas de intervenção governamental no semiárido, esse autor considera três períodos distintos: a) do processo de colonização do semiárido até a primeira metade do século XX, quando o governo pressionado pelas crises climáticas desenvolveu ações para combater a seca; b) a partir dos anos de 1950, quando o governo federal constata o atraso econômico do Nordeste em relação ao Centro-Sul do país e opta pela modernização econômica baseado na política de irrigação e da grande propriedade rural, enquanto continuava com medidas emergenciais nas épocas de seca; e c) o período em que políticas públicas para o semiárido tendem a passar por mudanças ocasionadas pela disputa entre diferentes concepções e alternativas de desenvolvimento (SILVA, 2010).

Neste último período, entra em debate a concepção de convivência com o semiárido para pautar não apenas as discussões sobre esse recorte territorial do Nordeste brasileiro, mas, 
sobretudo, a adoção de novas práticas e ações que possibilitem ao homem do campo a permanência na região. Com isso, vêm sendo modificadas as maneiras de intervir na realidade local, principalmente no que se refere às políticas públicas voltadas para as questões hídricas e educacionais.

Ao contrário da política de açudagem, a concepção de convivência com o semiárido acredita na possibilidade de adaptação da população às condições físico-climáticas da região, admitindo que a seca é um fenômeno natural que traz adversidades, empecilhos e limitações ao desenvolvimento socioeconômico da região, mas não determina seu subdesenvolvimento. A adaptação a essas condições trará, certamente, uma amenização dos impactos negativos causados pelas estiagens.

As leituras acerca do tema e do confronto entre as visões de modernização conservadora e as mais atuais de desenvolvimento (antes de tudo) social permitem compreender que a principal causa da situação de calamidade social na zona semiárida em épocas de estiagem prolongada não é exclusivamente a seca em si, mas determinadas características do sistema socioeconômico e político, como destacado por Silva (2010) ao afirmar que:

Há o reconhecimento de que não se pode nem se deve negar as características ecológicas, climáticas e culturais locais e nem delas fugir. Ou seja, a seca é uma questão ecológica, embora as suas consequências estejam relacionadas aos fatores socioeconômicos que predominam na região. Compreende-se que é possível desenvolver conhecimentos e soluções tecnológicas a partir de objetivos e valores que atendam às verdadeiras e legítimas aspirações da humanidade (SILVA, 2010, p.155).

Nessa perspectiva, a sociedade civil vem se mobilizando e o trabalho educacional sobre como conviver com o semiárido tem sido desenvolvido por órgãos governamentais e Organizações Não Governamentais (ONGs) que atuam no semiárido paraibano. Desse modo, estão sendo desenvolvidas algumas experiências voltadas para o manejo do solo, da água e da biodiversidade, com base em alternativas que utilizam tecnologias de baixo custo e buscam reduzir impactos negativos sobre o ambiente.

As tecnologias sociais, comumente oriundas de práticas alternativas inovadoras e não agressoras ao meio ambiente "já foram definidas como produtos, técnicas ou metodologias reaplicáveis, desenvolvidas em interação com a comunidade e devem representar efetivas soluções de transformação social" (MALVEZZI, 2007, p.105).

Algumas tecnologias sociais que ajudam na convivência com a realidade do assentamento em estudo podem sermencionadas neste momento, com distintos níveis de obtenção de sucesso e viabilidade em suas aplicações, a saber: cisternas de placa ou cisterna de bica, barreiros, açudes, poços e tanques de pedras. É importante ressaltar que, assim como Duarte (2002, p.17), compreende-se o termo "tecnologia" no sentido amplo, englobando tanto a infraestrutura e instrumentos, como também métodos. Descrições detalhadas sobre essas tecnologias e outras presentes no semiárido brasileiro podem ser encontradas em obras como a de Roberto Malvezzi, no seu livro intitulado de "Semi-Árido - uma visão holística"; Renato Duarte, em "O estado da arte das tecnologias para a convivência com as secas no Nordeste"; Roberto Marinho Alves da Silva, em 
"Entre o combate à seca e a convivência com o semi-árido: transições paradigmáticas e sustentabilidade do desenvolvimento", e em outras mais clássicas, como o livro "Solo e água no polígono das secas", de Guimarães Duque.

O contato com a realidade vivenciada pelos sujeitos sociais residentes no assentamento Serra do Monte revelou que a cisterna de placa (Figura 1) tem demonstrado bastante eficácia no objetivo de armazenamento de água para consumo humano.

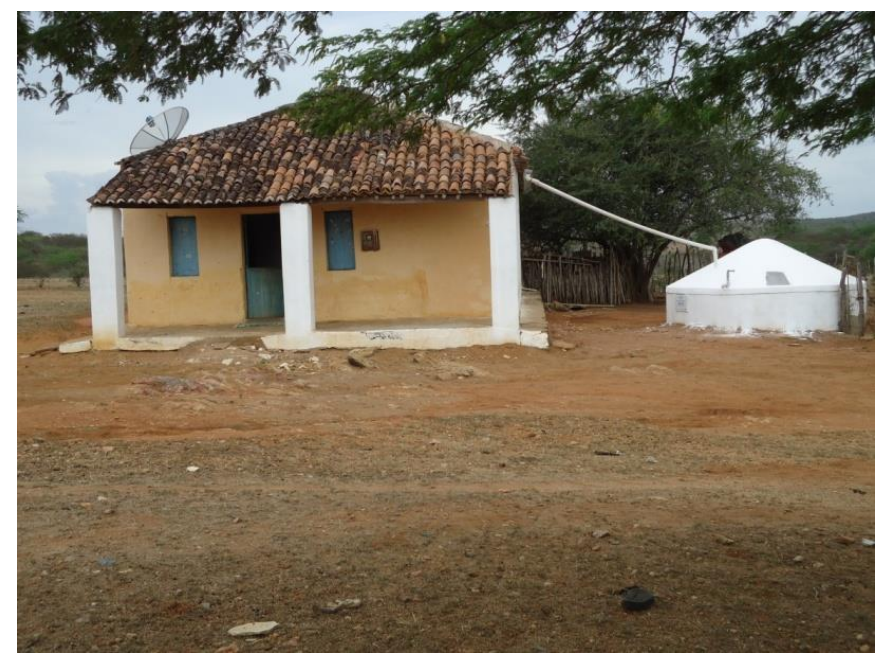

Figura 1 - Cisterna de placa em moradia do assentamento Serra do Monte. Fonte: Pesquisa de campo, novembro de 2014.

Essa tecnologia social vem tendo enorme difusão por meio do Programa Um Milhão de Cisternas Rurais (P1MC) ${ }^{5}$ do governo federal, implantado em 2003 pela a Articulação do Semiárido (ASA), o qual vem possibilitando a concretização do paradigma de convivência com o semiárido. $O$ objetivo dessa política hídrica é fornecer água potável para beber e cozinhar através da implantação de cisternas de placa para aquelas pessoas que moram no semiárido brasileiro. Além disso, este programa proporciona às famílias do lugar uma formação social que possibilita a compreensão de como conviver adequadamente com a semiaridez, principalmente, no que diz respeito ao gerenciamento da água e da cidadania. Essa política pública vem sendo apoiada pelos governos estaduais e municipais e pelas paróquias.

Quando bem administradas e zeladas, essas cisternas podem oferecer água potável de boa qualidade, pois a água da chuva recolhida dos telhados é conduzida diretamente para a cisterna, sem deixá-la cair no chão. Sobre o armazenamento, o uso e o manejo de água, Malvezzi (2007) destaca que:

Têm a nobre finalidade de oferecer água de qualidade para o consumo humano. Hermeticamente fechadas, não permitem a entrada da luz; assim, também não permitem a multiplicação de algas e outros elementos vivos. A água fica preservada. É feita de placas de argamassa construídas cerca de dois dias antes da montagem. Dois terços da cisterna ficam enterrados no chão, o que ajuda a

\footnotetext{
${ }^{5}$ Conforme podemos encontrar na página inicial do site el etrônico da ASA, 578.689 cisternas rurais foram construídas até o dia 25 de maio de 2015.
} 
compensar a pressão interna da água, dando estabilidade às paredes (MALVEZZI, 2007, p.107).

No processo de construção da cisterna em uma residência, o morador pode tentar obter ajuda - como orientações, materiais de construção, mão-de-obra, etc. - por meio de algum órgão ou instituição. Essa ajuda vem, em sua maioria, da ASA e do governo federal, além das associações comunitárias, da prefeitura municipal, da igreja ou de outras ONGs.

A implantação dessa tecnologia social nas residências dos assentados possibilitou diversas conquistas, dentre as quais destacam-se: a qualidade da água, a autonomia adquirida com a tecnologia, vez que a família pode autogerir seus recursos hídricos, além de diminuir alguns riscos ou problemas de saúde. Os depoimentos a seguir expressam a importância das cisternas de placa na reprodução da vida dos assentados.

“É uma das melhores coisas que já apareceu. Mudou muito a qualidade de vida do homem no campo. A gente desl ocava $5 \mathrm{~km}$ para pegar água que não era muito boa. Hoje, a cisterna ajudou bastante na captação de água. O uso da água da cisterna é apenas para o consumo humano" (J.S.A., presidente da Associação dos Parceleiros Agricultores Familiares do Imóvel Pocinhos, outubro de 2014).

"As pessoas absorvem as tecnologias e tem melhorado a sua vida" (J.A.P.S., presidente da Associação dos Agricultores e Familiares do assentamento Serra Monte, novembro de 2014).

Diante desse quadro de referência, considera-se a cisterna de placa como a tecnologia social que obteve mais sucesso em termos de viabilidade de implantação, facilidade de manutenção e apropriação e utilidade para armazenamento de água na área de estudo, e, provavelmente, em todo semiárido brasileiro. As cisternas evidenciam que o horizonte da convivência com o semiárido é real e que a população local dispõe de instrumentos capazes de evitar a extrema dependência de políticos e governos locais que se reproduziram, e em alguns casos ainda se reproduzem, por meio da indústria da seca.

Depois de cinco anos da implantação do P1MC, a ASA criou, no ano de 2007, o Programa Uma Terra e Duas Águas ( $1+2)$, o qual tem como finalidade garantir o acesso a terra aos camponeses (pequenos produtores), permitir que as pessoas tenham acesso a água para o consumo e saciar a sede dos animais. Este programa foi baseado na política chinesa chamada de $\mathrm{P} 1+2+1$, isto é, uma terra para produzir, duas cisternas e outra tecnologia que capte e armazene água de chuva. Nesse sentido, o P1+2 foi implantado no intuito de continuar o trabalho do P1MC.

Em relação aos pequenos reservatórios no assentamento Serra do Monte, constatou-se a presença de barreiros, que acumulam água da chuva. Nesse tipo de tecnologia há perdas consideráveis de água devido à evaporação, em decorrência das suas feições rasas e larga. Esses pequenos reservatórios são formas de armazenamento de água que se constituem numa alternativa àqueles que criam animais, vez que a água contida nessas tecnologias é utilizada livremente pelos animais, o que a torna imprópria para o consumo humano.

Além dos barreiros, os tanques de pedra (Figura 2) são bastante utilizados e se constituem numa alternativa de captação e armazenamento d'água. Assim, eles são definidos como 
"estruturas naturais localizadas em pedreiras de granito. Aproveita-se o cristalino que aflora nos solos sertanejos e constroem-se reservatórios quase naturais na pedra" (MALVEZZI, 2007, p.110). Geralmente, a água acumulada nos tanques de pedra é consumida pelos animais criados de forma extensiva, sobretudo caprinos e ovinos, e também são inadequadas para o consumo humano.

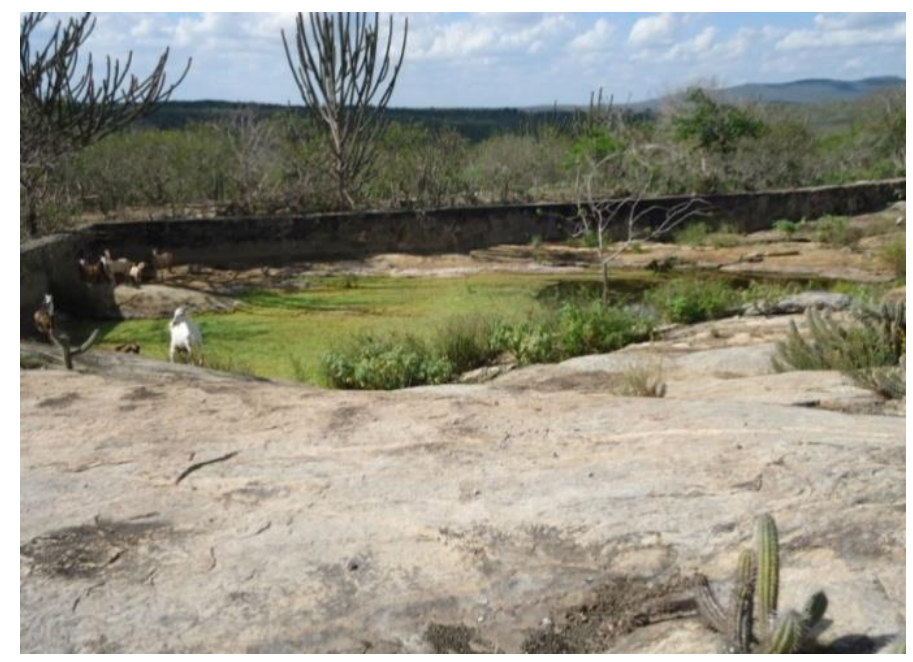

Figura 2 - Tanque de pedra em área do assentamento Serra do Monte. Fonte: Pesquisa de campo, outubro de 2013.

A implantação dessas tecnologias sociais e de outras, como por exemplo, poços e lagoas, podem ser considerados como um passo adiante nas formas de relacionamento do homem com o meio, na medida em que estão propiciando algumas conquistas, tanto na captação de água da chuva quanto na formação da cidadania. Isso porque as tecnologias sociais, por serem práticas e valorizar os saberes e técnicas locais, melhoram a qualidade da alimentação e da água, com desdobramentos positivos na saúde e na renda (MALVEZZI, 2007).

Empiricamente, verificou-se que alguns moradores desenvolvem métodos próprios para economizar água, em especial em épocas de estiagem prolongada. Nesse caso, fica valorizado o saber popular, aquele que não precisa de praticamente nenhum conhecimento de engenharia nem de estudos de materiais. Esse potencial dos moradores do assentamento faz parte da convivência com o semiárido e tem de ser valorizado nos programas a serem desenvolvidos pelo poder público local. Educar, ensinar e orientar a viver de maneira contextualizada é uma tarefa que requer, sobretudo, a valorização daquilo que eles já sabem, do que aprenderam na vivência, no dia a dia, nos momentos difíceis que passaram durante as diversas secas que afetaram a região.

As estratégias que estão sendo utilizadas e difundidas passam pelas mais diversas esferas do cotidiano do agricultor familiar que vive no assentamento Serra do Monte, o que está possibilitando aos sujeitos locais viverem de maneira contextualizada e respeitando as adversidades naturais da região. Para isso, buscam utilizar técnicas sustentáveis de modo a evitar o desgaste de solo e o desperdício da água.

Diante desse contexto, as políticas públicas, sobretudo as hídricas, que nesse trabalho foram apresentadas por meio das tecnologias sociais, evidencia o que Malvezzi (2007) ressalta sobre a convivência com o semiárido, "a qual visa focar a vida nas condições socioambientais da região, em seus limites e potencialidades, pressupondo novas formas de aprender e lidar com esse ambiente, para alcançar e transformar todos os setores da vida" (MALVEZZI, 2007, p.133). 
A concepção de convivência e a permanência no semiárido é um (re) aprendizado, uma pedagogia, um movimento de reorganização da sociedade, por certo ainda incipiente, mas que traz novos significados e sinaliza para a valorização do território, uma vez que:

é um reaprendizado da comunhão intrínseca entre os sujeitos e a realidade do semi-árido através das experiências vividas. A mudança de percepção sobre a realidade local e a experimentação de alternativas de produção apropriada pela população sertaneja é a principal garantia da convivência (SILVA, 2007, p.476).

Gustavo Maia Gomes (2001) em seu livro intitulado Velhas Secas em Novos Sertões chama atenção para o fato de que as secas de hoje já não afetam às populações como antigamente, tendo em vista que não há mais registros de mortes humanas em massa nos períodos de estiagem prolongada, até mesmo a redução dos rebanhos não tem como único motivo a falta de água e de alimento, mas a própria decisão dos proprietários em vendê-los. No caso dos migrantes, eles ainda existem, mas em menor número.

Durante a realização da pesquisa constatou-se que as tecnologias sociais hídricas, como as cisternas de placas, cisternas calçadões, barragens subterrâneas, dentre outras, estão contribuindo para esse novo contexto presente na realidade do semiárido, principalmente no momento atual, marcado por severa estiagem. Isso foi constatado por ocasião das atividades de campo, nas quais se verificou a extrema satisfação dos entrevistados em relação àquelas tecnologias, principalmente quando compararam a situação atual com épocas passadas em que se deslocavam para lugares distantes em busca de água nos períodos de seca. Foram inúmeros os relatos que expressaram a importância dessa tecnologia na vida dos sujeitos inquiridos. Como exemplo, tem-se os seguintes trechos: "agora tem água limpa para beber"; "agora melhorou porque a cisterna tem 16 mil litros e dá para passar de um ano para outro"; "a gente não precisa buscar água longe e carregar em lata na cabeça".

A partir dos depoimentos ficou evidenciado o quanto as tecnologias sociais hídricas, principalmente as cisternas de placas, contribuíram para uma expressiva melhoria na qualidade de vida dos moradores do assentamento na medida em que favoreceu a sua permanência no campo e impactou positivamente tanto na reprodução socioeconômica quanto na saúde dos membros das famílias que sofriam com doenças provocadas pelo uso de águas impróprias para o consumo.

Portanto, é possível dizer que a difusão dessa tecnologia social hídrica na área pesquisada está possibilitando a adoção da primeira regra de convivência com o semiárido que é captar água durante o período chuvoso e armazená-la para suprir as necessidades da população durante os períodos de estiagem prolongada e impedir a ocorrência do processo de evaporação que é um dos maiores problemas do manejo de água no semiárido. Essa pedagogia da convivência pressupõe complementaridade e interdependência. A proposta de aprender a conviver com o semiárido pressupõe o sentido das coisas a partir da vida cotidiana. Opera na dimensão comunitária, através da atuação no nível micro, onde é possível desenvolver novas perspectivas para a reapropriação subjetiva da realidade e abrir um diálogo entre o conhecimento e os saberes tradicionais, como ressaltado por Mattos (2004). 


\section{PREMISSAS DE CONCLUSÃO}

Apesar dos avanços alcançados na forma de lidar com a semiaridez, com a inserção e a mobilização de novos sujeitos sociais orientados numa perspectiva de convivência com o semiárido, ainda são inúmeros os desafios, porque há sinais evidentes de permanência das concepções e práticas/políticas que predominaram por muito tempo na região do Cariri paraibano.

Nos últimos tempos, a concepção de convivência com o semiárido (ainda incipiente) vem comprovando que a permanência dos assentados na área de estudo se faz possível graças à implantação de políticas públicas, principalmente aquelas de uso e manejo d'água, bem como aquelas que levam em consideração os aspectos educacionais e agrícolas. Deste modo, novos olhares estão sendo direcionados para os saberes tradicionais que valorizam o conhecimento e as tradições locais, aliando-os ao conhecimento científico produzido na atualidade.

A possibilidade de incorporar ações voltadas para a sustentabilidade e a inclusão social é algo em curso. Embora, a construção de cisternas de placas e o incentivo ao uso de outras fontes de captação e acumulação de água estejam amenizando os efeitos das secas periódicas e possibilitando a permanência do homem no meio rural, elas não são suficientes para as transformações socioeconômicas e a consolidação do paradigma da sustentabilidade e da convivência em toda a região do Cariri paraibano. É por isso que, apesar da importância assumida pelas tecnologias sociais aqui estudadas, a sua implantação e a própria visão de convivência com o semiárido não pode estar separada de mudanças estruturais.

No assentamento Serra do Monte, os desafios são muitos, mas as possibilidades de convivência com o semiárido são viáveis. Para isso, faz-se necessário que as ações a serem desenvolvidas nessa perspectiva sejam postas em prática e dialogadas cotidianamente para que sejam absorvidas culturalmente e politicamente, o que requer um envolvimento sério e comprometimento permanente por parte daqueles que estão envolvidos com os desafios presentes no espaço semiárido. Esse artigo também tem esse objetivo.

\section{REFERÊNCIAS}

1. AB'SABER, Aziz Nacib. Sertões e sertanejos: uma geografia humana sofrida. In: REVISTA DE ESTUDOS AVANÇADOS. São Paulo: USP, v. 13, n³6, 1999.

2. ANDRADE, Gilberto Osório de. Alguns aspectos do quadro natural do Nordeste. Recife, SUDENE, 1977 (Séries Estudos Regionais).

3. ANDRADE, Manuel Correia de. A problemática da seca. Recife: Liber Gráfica e Editora, 1999.

4. ARTICULAÇÃO DO SEMIÁRIDO - ASA. Disponível em: <http://www.asabrasil.org.br/portal/Default.asp>. Acesso em: 15 de julho de 2015.

5. CABRAL, Elisa Maria et al. (Org.) Os Cariris Velhos da Paraíba. João Pessoa: UFPB/ Editora Universitária e A União, 1977.

6. DUARTE, Renato Santos. $O$ estado da arte das tecnologias para a convivência com as secas no Nordeste. Fortaleza: Banco do Nordeste; Recife: Fundação Joaquim Nabuco, 2002.

7. DUQUE, José Guimarães. Solo e água no polígono das secas. 6a Ed. Mossoró: Coleção 
Mossoróense, 2001.

8. FERREIRA, Lúcia de Fátima Guerra. Raízes da indústria da seca: o caso da Paraíba. João Pessoa: Editora Universitária/UFPB, 1993.

9. INSTITUTO BRASILEIRO DE GEOGRAFIA E ESTATÍSTICA - IBGE. Censo Demográfico 2010. Disponível em: <http://www.ibge.gov.br>. Acesso em: 04 de agos to de 2014.

10. GOMES, Gustavo Maia. Velhas secas em novos sertões: Continuidade e mudança na economia do Semiárido e dos Cerrados nordestinos. Brasília: IPEA, 2001.

11. MALVEZZI, Roberto. Semi-árido - uma visão holística. Brasília: Confea, 2007.

12. MATTOS, Beatriz Helena Oliveira de Mello. Natureza e sociedade no semiárido brasileiro: um processo de aprendizagem social? In: Educação no contexto do semi-árido brasileiro. Fortaleza: Fundação Konrad Adenauer, 2004.

13. NIMER, Edmon. Pluviometria e recursos hídricos de Pernambuco e Paraíba. Rio de Janeiro: IBGE/SUPREN, 1979.

14. OLIVEIRA, Francisco de. Elegia pra uma re(li)gião: SUDENE, Nordeste. Planejamento e Conflitos de classes. 3a Ed. Rio de Janeiro: Paz e Terra, 1981, 132p.

15. PLANO DE RECUPERAÇÃO dO ASSENTAMENTO SERRA DO MONTE CABACEIRAS-PB: COOPAGEL, INCRA, Projeto Dom Helder Câmara, 2010, 82p.

16. REBOUÇAS, Aldo C. Água na Região Nordeste: desperdício e escassez. Revista Estudos Avançados, São Paulo, v. II, n. 29, p. 127-154, Jan/abril 1997. Disponível em: <http://www.scielo.br/pdf/ea/v11n29/v11n29a07.pdf>. Acesso em 24 de dezembro de 2014.

17. SILVA, Anieres Barbosa da. Políticas públicas e tecnologias sociais para convivência com o semiárido paraibano: um olhar sobre as experiências de uso e manejo de água no Cariri Paraibano. (Relatório de Pesquisa) UFPB/CNPq, João Pessoa, 2012.

18. SILVA, Pedro Carlos Gama da; MOURA, Magna Soelma B. de; KIILL, Lúcia Helena Piedade et al. Caracterização do Semiárido brasileiro: fatores naturais e humanos. In: SÁ, lêdo Bezerra; SILVA, Carlos Gama da (Orgs). Semiárido brasileiro: pesquisa, desenvolvimento e inovação. Petrolina: Embrapa Semiárido, 2010, p. 17-48.

19. SILVA, Roberto Marinho Alves da. Entre o combate à seca e a convivência com o semi-árido: transições paradigmáticas e sustentabilidade do desenvolvimento. Reimp. Fortaleza: Banco do Nordeste do Brasil, 2010.

20. _. Entre o combate à seca e a convivência com o Semiárido: políticas públicas e transição paradigmática. In: Revista Econômica do Nordeste. Fortaleza, v. 38, n³, jul-set 2007.

21. SILVA, Suayze Douglas da. Tecnologias sociais hídricas para convivência com o semiárido no Assentamento Serra do Monte, Cabaceiras-PB. 2015. 55p. Monografia (Bacharelado em Geografia) - UFPB, João Pessoa (PB).

22. SOUZA, Bartolomeu Israel de. Cariri Paraibano: do silêncio do lugar à desertificação. Tese (Doutorado em Geografia) - Universidade Federal do Rio Grande do Sul - UFRGS, Porto Alegre, 2008. 